Revista de Comunicación y Salud, 2018, Vol. 8, no 1, pp. 127-136

Editado por Cátedra de Comunicación y Salud

ISSN: 2173-1675

Enviado 19 de octubre de 2018

Aprobado 22 de noviembre de 2018

\title{
CRISIS DEL BROTE DEL DENGUE EN ESPAÑA EN 2018: SU ANÁLISIS EN LOS DIARIOS LA VERDAD, EL PAÍS Y EL MUNDO
}

\author{
Crisis of the dengue outbreak in Spain in 2018: its analysis in the newspapers La \\ Verdad, El País and El Mundo \\ Rafael Barberá Gonzaléz \\ Universidad Complutense de Madrid
}

\begin{abstract}
Resumen
Al aparecer un brote sobre una enfermedad poco habitual en un país determinado surge una situación de crisis. Los ciudadanos no conocen bien las decisiones que deben tomar para hacer frente a la enfermedad y acuden a los medios de comunicación para tratar de obtener información. Éstos, a su vez, la encuentran en las diversas fuentes que les pueden facilitar datos, medidas, consejos, etc. En la segunda mitad de 2018 apareció un brote de dengue en España, un hecho que tuvo repercusión mediática porque fueron varias las personas que se vieron afectadas. En este trabajo se analiza cómo fue el tratamiento informativo de esta crisis en tres periódicos. Dos de ámbito nacional, El País y El Mundo, y otro regional, La Verdad, dado que fue en Murcia donde se dieron los casos más relevantes. Además de establecer las pautas que se llevan a cabo en una comunicación de crisis, en general, y de carácter sanitario, en particular, se abordan las coberturas informativas de los medios citados durante un periodo de tiempo concreto. Se trata de comprobar cómo un riesgo sanitario (el dengue) es tratado por los medios para que los ciudadanos dispongan de las claves necesarias para saber actuar.
\end{abstract}

Palabras clave: crisis, comunicación, dengue, información, Murcia, España.

\begin{abstract}
When an outbreak appears on a rare disease in a given country, a crisis situation arises. Citizens do not know well the decisions they must make to deal with the disease and go to the media trying to obtain information. These, in turn, find it in the various sources that can provide them with data, measurements, advice, etc. In the second half of 2018 an outbreak of dengue appeared in Spain, a fact that had media repercussion because there were several people who were affected. In this paper we analyze how was the information treatment of this crisis in three newspapers. Two national, El País and El Mundo, and another regional, La Verdad, given that it was in Murcia where the most relevant cases occurred. In addition to establishing the guidelines that are carried out in a crisis communication, in general, and of a sanitary nature, in particular, the information coverage of the aforementioned media is addressed during a specific period of time. It is about checking how a health risk
\end{abstract}


(dengue) is treated by the media so that citizens have the necessary keys to know how to act.

Keywords: crisis, communication, dengue, information, Murcia, Spain.

\section{Cómo citar el artículo}

Barberá Gonzaléz, R. (2018). Crisis del brote del dengue en España en 2018: su análisis en los diarios La Verdad, El País y El Mundo. Revista de Comunicación y Salud, 8(1), pp. 127-136.

DOI: http://doi.org/10.35669/revistadecomunicacionysalud.2018.8(1).127-136

\section{INTRODUCCIÓN}

\subsection{Cronología}

El 22 de agosto de 2018 un hombre de alrededor de 50 años, residente en Alhama (Murcia), acude a su centro de salud con fiebre y otros síntomas. Al día siguiente es atendida, en el mismo centro, su suegra, de unos 70 años.

El 29 de agosto el mismo paciente de Alhama acude a Urgencias del Virgen de La Arrixaca. Se le tratan los síntomas, sin un diagnóstico específico, y se le da de alta.

El 19 de septiembre La Arrixaca solicita una serología para averiguar si los dos pacientes han padecido dengue. La decisión se toma después de que un hospital madrileño enviase muestras de una tercera persona, residente en Madrid pero familiar de los dos afectados de Alhama, al Centro Nacional de Microbiología por sospecha de dengue. Los tres coincidieron físicamente en la Región durante el periodo de incubación.

El 29 de septiembre un joven de 19 años, residente en Cabezo de Torres, ingresa en el Morales Meseguer con fiebre alta y otros síntomas compatibles con el dengue. Se solicita serología de confirmación.

El 4 de octubre el padre del joven, de 53 años, acude al Morales Meseguer con los mismos síntomas. Ese mismo día, el Centro Nacional de Microbiología confirma que los pacientes de Alhama padecen dengue, lo que se hace público el día 9, según se recoge en el diario La Verdad (2018).

\subsection{Crisis: su comunicación}

El Diccionario de la Lengua española define de esta manera el término 'crisis':

1. Cambio profundo y de consecuencias importantes en un proceso o una sit uación,o en la manera en que éstos son apreciados.

2. Intensificación brusca de los síntomas de una enfermedad.

3. Situación mala o difícil.

4. Situación política en que uno o más miembros del Gobierno han dimitido han sido destituidos. 
5. Reducción en la tasa de crecimiento de la producción de una economía, o fase más baja de la actividad de un ciclo económico.

6. Cambio brusco en el curso de una enfermedad, ya sea para mejorarse, ya para agravarse el paciente.

7. Examen y juicio que se hace de algo después de haberlo examinado cuida dosamente (RAE, 2017).

Al objeto del presente artículo las tres primeras acepciones son las que más relevancia tienen porque el brote del dengue supuso un cambio profundo, creó una situación difícil y, además, con su aparición se intensificaron los síntomas de una enfermedad.

Aunque son muchos los autores que han tratado de definir este concepto la aportación dada por la compañía Pacific Telesis, matriz de Pacific Bell, goza de un amplio consenso. En su manual sobre comunicación en tiempos de crisis, establece que "una crisis es un acontecimiento extraordinario, o una serie de acontecimientos, que afecta de forma adversa a la integridad del producto, a la reputación o a la estabilidad financiera de la organización" (Martínez Fernández, 2008).

Comunicar a los diferentes públicos una crisis o situación de riesgo se convierte en una situación compleja porque son muchos factores los que entran en juego. Desde estudios científicos que pueden resultar contradictorios hasta informaciones que pueden incluir contenidos equívocos pasando por percepciones distintas en los públicos afectados.

A la hora de comunicar un riesgo Sandman (1994) establecía siete principios que deben tenerse en cuenta. Destacamos dos por su relación con el caso del brote de dengue:

a) Cuando en las noticias se proporciona información técnica sobre el riesgo, tiene poco o ningún impacto en la audiencia.

b) Los periodistas se apoyan más en fuentes oficiales.

\subsection{Crisis sanitarias}

De la amplia tipología de crisis existente, aquellas que están relacionadas con la salud han requerido de una mayor dedicación por parte de los profesionales en los últimos años. La razón descansa en que, cada vez más, los ciudadanos se preocupan por su salud.

En España, según se recoge en el Barómetro del Centro de Investigaciones Sociológicas de octubre de 2018, la sanidad ocupa el sexto lugar en las preocupaciones de los españoles.

\begin{tabular}{|c|c|}
\hline Preocupación & $\%$ \\
\hline Paro & 59,8 \\
\hline Corrupción y fraude & 30,5 \\
\hline $\begin{array}{c}\text { Los políticos en general, los partidos } \\
\text { políticos y la política: }\end{array}$ & 27,8 \\
\hline Problemas de índole económica & 21 \\
\hline
\end{tabular}


Crisis del brote del dengue en España en 2018: su análisis en los diarios

La Verdad, El País y El Mundo

\begin{tabular}{|c|c|}
\hline La independencia de Cataluña & 12,2 \\
\hline Sanidad & 11,1 \\
\hline
\end{tabular}

Fuente: CIS. Elaboración propia.

Un puesto relevante dado que se pregunta por 42 ítems, algunos de ellos tan significativos como las pensiones, la inmigración, la educación o los problemas de índole social, por ejemplo.

Los medios de comunicación tratan de cubrir esta necesidad y ofrecen informaciones, análisis, gráficos, etc., para llegar con claridad a sus audiencias. Desde la perspectiva teórica de la Agenda Setting se observa que si un tema determinado tiene un mayor énfasis mediático "tiende a provocar en la opinión pública una mayor preocupación sobre ese tema" (Igartua, Muñiz, Otero y De la Fuente, 2007).

Esta alerta se da especialmente al inicio de un brote (como el del dengue). En estos primeros momentos los medios de comunicación desempeñan un papel "decisivo en el riesgo percibido por la población, que a veces puede alejarse mucho del riesgo real” (Hernández-Aguado y Ramírez, 2006).

Como el público tiene acceso a un mayor número de canales informativos crece la responsabilidad de todos los actores implicados, también la de los especialistas en gestionar situaciones de crisis. En función de cómo sea la información que se traslada a los diferentes públicos, será la percepción de éstos. Cuando nos encontramos ante una situación de riesgo, los investigadores identifican diversas variables que pueden afectar a esta percepción. Así lo señalan Wilcox, Cameron y Xifra (2007):

a) Los riesgos asumidos de forma voluntaria tienden a ser mejor aceptados que aquellos sobre los que los individuos tienen poco o ningún control.

b) Cuanto más compleja sea la situación, mayor será la sensación de riesgo.

c) La familiaridad aumenta la confianza. Si el público entiende el problema y sus factores de riesgo, percibirá menos riesgos.

d) La percepción del riesgo aumenta cuando los mensajes de los expertos son contradictorios.

e) La gravedad de las consecuencias afecta a la percepción del riesgo.

\subsection{Comunicación sobre el dengue}

La Organización Mundial de la Salud explica que es el mosquito 'Aedes aegypti' el principal vector de los virus que causan el dengue. $Y$ añade en su página web que "los seres humanos se infectan por picaduras de hembras infectadas, que a su vez se infectan principalmente al succionar la sangre de personas infectadas" (OMS, s.f.).

Para concienciar a los públicos sobre la vigilancia y control de este mosquito, la Organización Panamericana de la Salud (2016) estableció una guía de mensajes. Entre ellos, por ejemplo, apuntaba que "es necesario educar al paciente, a otros miembros del hogar y a la comunidad acerca del riesgo de transmisión y las medidas para disminuir la cantidad de mosquitos y el contacto entre el vector y las personas". 
En el caso concreto que se analiza en este trabajo el Ministerio de Sanidad, Consumo y Bienestar Social hizo pública una nota de prensa el 9 de octubre en la que hacía un repaso de lo ocurrido hasta entonces. El Centro Nacional de Microbiología del Instituto de Salud Carlos III había confirmado el 4 de octubre dos casos de infección por virus dengue en adultos residentes en España. Añadía que los resultados de un tercer caso, una mujer adulta con síntomas compatibles con la enfermedad, estaban pendientes de confirmación. Se indicaba que las tres personas habían tenido sus primeros síntomas durante la segunda quincena de agosto y que en ese momento presentaban buen estado de salud. De los tres, dos de ellos residían habitualmente en la Región de Murcia y el otro en la Comunidad de Madrid.

Además de explicar en qué consistía el dengue se señalaba que se había iniciado un seguimiento continuo de este evento.

Por último la citada nota mencionaba que se había reforzado la comunicación y sensibilización "a los profesionales sanitarios y de laboratorios sobre la detección precoz y notificación oportuna en caso de que aparecieran nuevos casos" (Ministerio de Sanidad, 2018). Se advertía también que debido a la época del año y a las medidas adoptadas por las autoridades de salud pública, la probabilidad de transmisión autóctona en ese momento era muy baja.

\section{OBJETIVOS E HIPÓTESIS}

El objetivo general de este trabajo es monitorizar el tratamiento informativo en las ediciones digitales de tres diarios, en concreto La Verdad, El País y El Mundo, durante un periodo de tiempo representativo, sobre el brote del dengue detectado en 2018 en España.

Como objetivos específicos cabe destacar:

1.- Ordenar y clasificar la información en estos periódicos.

2.- Analizar las noticias aparecidas para saber aspectos como: cobertura, firmas, géneros y revisión de titulares.

Por lo que a las hipótesis se refiere, al ser un trabajo descriptivo, se plantean en su lugar research questions (RQ) siguiendo a autores como Katz (1957).

RQ1: En función de los aspectos propuestos, ¿es posible analizar las informaciones que publican estos tres diarios?

RQ2: ¿Qué tipo de información llega al lector sobre el brote del dengue?

\section{MÉTODO}

La monitorización se llevó a cabo durante un mes. Desde el 9 de octubre, que es el día en que el Ministerio de Sanidad emitía una nota de prensa sobre el brote del dengue. En las ediciones digitales de los periódicos seleccionados se buscó 'dengue' como palabra clave.

La elección de estos tres diarios viene dada por sus relevantes datos de tirada y difusión, en promedio y desde julio de 2017 a junio de 2018. El País cuenta con una 
tirada de 215.877 ejemplares y una difusión de 163.759, mientras que la tirada de El Mundo es de 135.828 ejemplares y su difusión es de 93.635. Además, se ha elegido La Verdad porque, en la región de Murcia, es el diario que cuenta con mayores cifras: 15.644 ejemplares de tirada y 12.653 de difusión (OJD, 2018).

Se han analizado las ediciones digitales de estos medios porque la información que se publica en este soporte es de más fácil acceso a los públicos afectados. Y se ha preferido prensa porque las noticias aparecidas en radio o televisión nos llevarían a analizar una gran cantidad de datos.

La preferencia por estos tres diarios, y no por otros, descansa también en que pertenecen a grupos editoriales distintos que aportan enfoques ideológicos distintos sobre cuestiones de actualidad.

\section{RESULTADOS Y DISCUSIÓN}

\subsection{Cobertura}

Desde que se conocieron los primeros datos del brote del dengue, los medios de comunicación comenzaron a publicar informaciones. Fue 9 de octubre de 2018 cuando se informó de que había dos afectados y que eran vecinos de Alhama (Murcia). Así lo confirmaron desde la Dirección General de Salud Pública y Adicciones, en la Región de Murcia, y desde la Unidad de Medicina Tropical del Hospital Virgen de la Arrixaca de Murcia.

A partir de ese momento los medios debían tener en consideración un elemento clave en la responsabilidad social que se les atribuye: "no generar alarmismo innecesario y no provocar situaciones de pánico" (García Frontiñán, 2016).

Los periódicos que se analizan en este trabajo realizaron una cobertura dispar. Mientras que El País y El Mundo ofrecieron informaciones puntuales a medida que se iban conociendo los casos ya diagnosticados, La Verdad dedicó más espacio debido a que fue en la región murciana donde mayor presencia tuvo este brote.

Aunque era una noticia de salud, y así fue tratada prioritariamente, también tuvo repercusiones políticas.

En cuanto al número total de informaciones, incluyendo los distintos géneros, publicadas por estos periódicos, El País lo hizo en 5 ocasiones, El Mundo en tres, y La Verdad, en 16.

En el mes analizado las noticias fueron decreciendo con el paso de los días, algo que es comprensible porque el brote fue desapareciendo y con él, el interés de los públicos.

\subsection{Firmantes de las noticias}

Dado que la primera información salió de un comunicado de una fuente oficial, buena parte de las noticias analizadas en este trabajo tienen su origen en las agencias.

Revista de Comunicación y Salud, 2018, Vol. 8, № 1, pp. 127-136 
En el caso de El País el redactor elegido para firmar sus informaciones es un periodista que escribe sobre cuestiones relacionadas con la sanidad. El Mundo se decanta, sin embargo, por las agencias excepto en el caso de una columna de opinión firmada por un especialista. En cuanto a La Verdad combina las agencias con periodistas del periódico especializados en las secciones de sanidad, reportajes e información local.

Además, se utiliza, en este apartado, la modalidad de 'genérico o sin firma', esto es, aparece solo el nombre del diario. Este hecho no significa que en esos textos se fije la posición editorial del medio porque existen otros espacios que sirven para dar a conocer la opinión.

\subsection{Géneros}

Si atendemos a las clasificaciones más clásicas de los géneros periodísticos hay que señalar la que diferencia los informativos de los interpretativos y de los de opinión.

En los periódicos analizados el género que predomina es el de la información. De las 24 piezas, 23 son noticias, incluyendo los gráficos de apoyo, los despieces que sirven para aclarar datos al lector y la sección de 'preguntas y respuestas', que ofrece El Mundo. Esta mayoría se debe a que estos diarios dedican un mayor espacio a este género y también a que durante el periodo analizado surgieron numerosas noticias sobre el brote del dengue. En cuanto al género del opinión solo El Mundo le dedica atención al publicar una columna firmada por un especialista. $\mathrm{Y}$ en este tiempo los diarios no publican ninguna pieza del género interpretativo, probablemente porque la realidad del brote fue a menos con el paso de los días.

\subsection{Revisión de titulares}

El tratamiento en las piezas de carácter informativo es muy similar en los tres diarios analizados. Así, en los primeros momentos El País (2018) titulaba: "Detectados los primeros casos autóctonos de dengue en España", mientras que en El Mundo (2018) podía leerse: "Confirmados en Murcia dos casos de dengue contraído en España", y en La Verdad (2018): "Confirmados dos casos de dengue contraído en España". Se aprecia por tanto que incluso se emplean los mismos términos.

También desde el principio los diarios se inclinan por ofrecer explicaciones a sus lectores sobre el dengue. Parece evidente que la audiencia pretenda encontrar respuestas a sus preguntas y El Mundo se las ofrece en la pieza del 17 de octubre, titulada "¿Qué es el dengue y cuáles son sus síntomas?". Y La Verdad, por su parte, lo hace en los titulares publicados el 10 de octubre: "Síntomas del dengue: una fiebre 'quebrantahuesos' que se confunde con una gripe" y "Dengue: transmisión, síntomas y áreas con riesgo". Lógicamente el diario de Murcia fue el que mayor espacio le dedicó a informar de este brote dado que los casos fueron detectados en esta región. 
Este hecho y las declaraciones sobre él, aunque afectaban a la salud, también tuvieron su vertiente política. Y fue La Verdad el periódico que, por las razones de proximidad ya expuestas, se ocupó de ellas. Así, se destaca que el 10 de octubre titulara: "José Carlos Vicente: "Nos toca convivir con el mosquito tigre»", una pieza que recogía las manifestaciones del director general de Salud Pública y Adicciones, José Carlos Vicente, y del doctor Manuel Segovia, jefe del Servicio de Microbiología y de la Unidad de Medicina Tropical del Hospital Virgen de la Arrixaca de Murcia. En el ámbito de la política, al día siguiente, se difundían las declaraciones de María Luisa Carcedo, ministra de Sanidad, Consumo y Bienestar Social, en las que aseguraba que "Los casos de dengue son puntuales; en invierno no hay ningún riesgo".

Dos días después, el 13 de octubre, se informaba sobre el registro de una iniciativa parlamentaria de Ciudadanos en el Congreso de los Diputados: "Cs pregunta en el Congreso por los protocolos de actuación frente al virus del dengue". Y, por último, el 6 de noviembre se publicaba la noticia de que el consejero de Salud, Manuel Villegas, comparecería en la Asamblea Regional de Murcia para explicar el procedimiento y protocolo desarrollado por la aparición del brote del dengue: "Villegas comparecerá en la Asamblea para explicar el protocolo de actuación por dengue".

\section{CONCLUSIONES}

En el epígrafe de los objetivos se plantearon las siguientes Research Questions:

RQ1: En función de los aspectos propuestos, ¿Es posible analizar las informaciones que publican estos tres diarios?

Las informaciones que aparecen en El País, El Mundo y La Verdad no solo son analizables sino que además se pueden clasificar. Atendiendo a los aspectos propuestos, cobertura, firmantes, géneros y revisión de los titulares, se encuentran temas bien definidos. Un hecho que se aprecia de manera sobresaliente en el diario de la región de Murcia dado que los casos se detectan en esa zona.

Es en La Verdad donde, además de ofrecerse una mayor cobertura del hecho, se cuenta con un mayor número de redactores propios como firmantes de las informaciones. Y de la lectura de sus titulares se colige que dedica una atención mayor a los diferentes ángulos informativos que supone el brote.

RQ2: ¿Qué tipo de información llega al lector sobre el brote del dengue?

A los lectores de los tres periódicos les llega información detallada en diferentes géneros. Prevalecen las noticias, con la posibilidad de examinar datos a través de gráficos. Esto sucede porque los públicos, en un principio, buscan tener detalles sobre el brote pero al no ir a más no es necesario acudir a interpretaciones 0 valoraciones sobre posibles contagios, etc.

En todo caso, y para obtener un mayor detalle, pueden acudir a una columna de opinión de un especialista en la materia. 


\section{BIBLIOGRAFÍA}

Camacho, I. (2009). La 'gripe A', en la prensa española. Revista Latina de Comunicación Social, 64, 827 - 843.

CIS (2018). Problemas que existen actualmente en España. Madrid: CIS.

Recuperado de http://www.cis.es/cis/export/sites/default/-

Archivos/Indicadores/documentos_html/TresProblemas.html

El Mundo (2018). Confirmados en Murcia dos casos de dengue contraído en España.

Recuperado de https://www.elmundo.es/ciencia-ysalud/ciencia/2018/10/09/5bbcd92c468aeb8a428b460f.html.

El País (2018). Detectados los primeros casos autóctonos de dengue en España. Recuperado de https://elpais.com/sociedad/2018/10/09/actualidad/1539103287_513910.html

García Frontiñán, E. (2016). Comunicación de crisis en los gabinetes de prensa sanitarios. Análisis de la producción periodística y de la información publicada sobre la gripe A. (Memoria de Doctorado). Facultad de Ciencias de la Información, Universidad Complutense de Madrid. Madrid.

Hernández-Aguado, I. y Ramírez, R. (2006). El impacto sanitario de los medios de comunicación en las alertas sanitarias. El caso de la gripe aviaria. Enfermería Clínica, 16(3), 109-111.

Igartua, J. J.; Muñiz, C.; Otero, J. A. y De la Fuente, M. (2007). El tratamiento informativo de la inmigración en los medios de comunicación españoles. Un análisis de contenido desde la Teoría del Framing. Estudios sobre el Mensaje Periodístico, 13, 91-110.

Katz, E. (1957). The Two-Step Flow of Communication: An Up-To-Date Report on an Hypothesis. Public Opinion Quarterly, 21(1), 61-78.

La Verdad (2018). Confirmados dos casos de dengue contraído en España. Recuperado de https://www.laverdad.es/sociedad/confirmados-casos-dengueespana-20181009192147-ntrc.html

La Verdad (2018). Cronología del brote. La Verdad. Disponible en https://www.laverdad.es/murcia/numero-afectados-brote-20181103011032ntvo.html

Martínez Fernández, V. A. (2008). Las nuevas tecnologías de la información en la definición de estrategias de comunicación ante situaciones de crisis. Hologramática, V(9), 25-56.

Ministerio de Sanidad, Consumo y Bienestar Social (2018). Detectados dos casos de dengue sin antecedentes de viaje a zonas con transmisión del virus. Recuperado de http://www.mscbs.gob.es/gabinete/notasPrensa.do?id=4393

OJD (2018). Medios controlados. Diarios. Recuperado de https://www.ojd.es/medioscontrolados/

Organización Mundial de la Salud (s.f.). Lucha contra el dengue. Recuperado de https://www.who.int/denguecontrol/mosquito/es/

Organización Panamericana de la Salud (2016). Guía de mensajes claves para dirigir a individuos y familias sobre la vigilancia y control del Aedes aegypti transmisor del dengue, chikungunya, zika y otras arbovirosis en las Américas. Recuperado de https://www.paho.org/hq/dmdocuments/2016/2016cha-mensajes-claves-control-aedes-aegypti.pdf

Real Academia Española (2017). Definición de crisis. Madrid: Real Academia Española. Recuperado de http://dle.rae.es/?id=BhwUydm. 
Crisis del brote del dengue en España en 2018: su análisis en los diarios

La Verdad, El País y El Mundo

Sandman, P. M. (1994). Mass Media and Environmental Risk: Seven Principles. RISK: Health, Safety \& Environment, 5(3), 251-260.

Wilcox, Dennis L; Cameron, Glen T; y Xifra, J. (2007). Relaciones públicas. estrategias y tácticas. Madrid: Pearson Addison Wesley. 